\title{
Evaluating the Effect of the Injectable PRF in Comparison with The Hyaluronic Acid as an Intra-articular Medication Following Arthrocentesis in the Treatment of Internal Derangement
}

Original

Article
Mosaad Abdaljawwad Abdalmawla Khalifah

Department of Oral and Maxillofacial Surgery, Faculty of Dentistry, Kafr ElSheikh

University, Egypt

\begin{abstract}
Background: Internal derangement (ID) is the most common cause for TMDs. Various invasive, minimally invasive, and non-invasive treatment modalities have been attempted. Arthrocentesis as a minimally invasive maneuver either if followed with various intra-articular medications or not has been attempted to treat ID. Hyaluronic acid (HA) has been used as an intraarticular medication due to its lubricant effect that improves joint movement and mechanically reduces friction pain. However, the i-PRF had both anti-inflammatory action to reduce the level of the cytokines; aided by the regenerative capacity to the torn and degenerated tissues of the joint including the synovial tissue.

Purpose: The current study aimed at comparing both factors.

Materials and Methods: Forty TMJs from thirty patients were randomly divided into two equal groups. In group I, arthrocentesis was followed by intra-articular injection of AH; however, in group II, arthrocentesis was followed i-PRF injection.

Results: In general, group II patients recorded better results with respect to clicking, pain, and movement limitation. Superior results of i-PRF might be the result of the regenerative capability that not only reduced the existing inflammatory mediators; but also replaced the degenerated cytokines-releasing tissues by healthy synovial fluid-releasing tissues provides endogenous sustained source of HA.
\end{abstract}

Conclusion: Although both treatments are acceptable, i-PRF was a rather recommended treatment.

Key Words: Hyaluronic acid, internal derangement, i-PRF, regeneration, temporomandibular joint disorders

Received: 30 December 2020, Accepted: 30 January 2021

Corresponding Author: Mosaad Abdaljawwad Abdalmawla Khalifah, Department of Oral and Maxillofacial Surgery, Faculty of Dentistry, Kafr ElSheikh University, Egypt, Tel.: 0021008603084, Mobile:, E-mail: mosaad_khalifa@den.kfs. edu.eg,mosaad78@hotmail.com.

ISSN: 2090-097X, July 2020, Vol. 11, No. 4

\section{INTRODUCTION}

Internal derangement (ID) is the most common cause for temporomandibular joint disorder (TMD) and accounts for more than $40 \%$ of TMDs. ID refers to the abnormal relationship of the articular disc to the mandibular condyle $^{[1]}$. Manifestations of ID are clicking, pain, and limitation of the mandibular movement and according to the severity of these signs and symptom the disease is classified according to many systems. Wilkes staging system is a very commonly used system (Table 1$)^{[2]}$.

However, the treatment if ID is mainly directed towards relieving pain on rest and function and to reestablish a normal range of movement of the mandible. Various treatment modalities have been advocated for the condition including the noninvasive, minimally invasive, and noninvasive methods. Occlusal therapy, physiotherapy, chemotherapy, and psychotherapy are examples of the noninvasive modalities. On the other hand, open TMJ surgeries such as discectomy, discoplasty, etc. are examples of the invasive modalities. Arthrocentesis and arthroscopy are the examples of the third in-between group which is the minimally invasive modality ${ }^{[1,3-13]}$. Arthrocentesis either followed with intra-articular injections, or not has gained a large deal of interest [7, 10,14-16]. Arthrocentesis has its therapeutic effect by releasing adhesions, releasing intraarticular negative pressure, and washing out inflammatory mediators such as cytokines; thereby it relieves pain and improves joint function ${ }^{[17-22]}$. Arthrocentesis might be performed alone or followed by intra-articular injection of variant substances such as hyaluronic acid (HA), corticosteroids, morphine, platelet-derived growth factor [PDGF] $^{[10,14,15,21-24]}$. Hyaluronic acid (HA) is the main constituent of the synovial fluid that is naturally released by the synovial cells into the joint and has a pivotal role in lubrication. As a therapeutic material for intra-articular injection, it has been proved to reduce pain and improve the mouth opening ${ }^{[21-24]}$. Another intra-articular injection material which is the plasma rich in platelet-derived growth factors (PRGFs) has been employed to regenerate the synovial tissues and the other degenerated tissues in the joint. Although platelet rich fibrin (PRF) is a plasma product that is rich in platelet-derived growth factors and was widely used in many maxillofacial diseases for its 
highly regenerative capacity, however, its use in the TMDs was limited to open joint surgeries because PRF has a three-dimensional matrix makes it in-injectable. Therefore, a novel technique based on low speed centrifugation resulted in the introduction of the liquid PRF to enable the injection ability of that valuable material. This liquid PRF known as injectable PRF (i-PRF) has a concentration of leukocytes and various growth factors particularly vascular endothelial growth factor (VEGF) and transforming growth factor-beta (TGF- $\beta$ ) greater than that found in the ordinary $\mathrm{PRF}^{[25,26]}$. Leukocytes are well-known connector cells in the chain of cell-cell communication between the precursor cells and mesenchymal cells with regard to tissue regeneration and wound healing. Away from their antimicrobial effect, leukocytes participate in angiogenesis and lymphogenesis; and thereby enhance the regenerative environment. Accordingly, leukocytes and their subgroups play a crucial role in wound healing and regeneration processes. Vascular endothelial growth factor (VEGF) and transforming growth factor-beta (TGF- $\beta$ ) which are released only after platelet aggregation are crucial protagonists to modulate the various phases during tissue regeneration and wound healing. The interplay between the leukocytes and the growth factors provide the synergistic modulation effect in the cell-cell signaling cascade in the regeneration process. Since i-PRF is a very recent product, it was used in some limited number of studied on TMDs, but with promising results with regard to pain and limitation of movement ${ }^{[14,24,27-29]}$. Therefore, the current study aimed at evaluating the effect of the i-PRF in comparison with the HA as an intra-articular medication following arthrocentesis in the treatment of ID.

\section{PATIENTS AND METHODS}

Subjects : A total of 40 TMJs for 30 patients with ID as diagnosed by the clinical picture and the MRI findings (In the view of table 1) were included in the current study from the outpatient department of Oral and Maxillofacial Surgery Department within the age range of 15 to 55 years (mean age 23.19 years) were included in the current study. Inclusion criteria involved an otherwise healthy patient suffered clicking, peri-joint pain, and limitation of mandibular movement who did not receive any medications within the previous three months. Exclusion criteria included any disease could affect healing, hormonal disturbances (including DM), any bone or connective tissue disease, psychological disease and bleeding or coagulation disorders. Any patient with positive MRI findings but has no clinical symptoms was excluded. Patients were randomly divided into two equal groups using a computer permuted block stratified randomization generator (randomization.com).
Table 1: Stages and features of internal derangement

\begin{tabular}{|c|c|c|}
\hline Stage & Clinical features & $\begin{array}{l}\text { Radiographical } \\
\text { features }\end{array}$ \\
\hline I (early) & $\begin{array}{l}\text { Clicking, no pain, } \\
\text { no limitation } \\
\text { in motion }\end{array}$ & $\begin{array}{l}\text { Slight disc } \\
\text { displacement with } \\
\text { early reduction, } \\
\text { normal disc } \\
\text { morphology }\end{array}$ \\
\hline $\begin{array}{l}\text { II (early/ } \\
\text { intermediate) }\end{array}$ & $\begin{array}{c}\text { Clicking, } \\
\text { occasional pain, } \\
\text { intermittent } \\
\text { locking, headache }\end{array}$ & $\begin{array}{l}\text { Moderate disc } \\
\text { displacement } \\
\text { with late } \\
\text { reduction, mild } \\
\text { disc deformity }\end{array}$ \\
\hline III (intermediate) & $\begin{array}{l}\text { Clicking, } \\
\text { frequent pain, } \\
\text { joint tenderness, } \\
\text { restricted motion, } \\
\text { closed lock }\end{array}$ & $\begin{array}{l}\text { Disc displacement } \\
\text { without reduction, } \\
\text { moderate disc } \\
\text { deformity, no hard } \\
\text { tissue changes }\end{array}$ \\
\hline $\begin{array}{l}\text { IV (intermediate/ } \\
\text { late) }\end{array}$ & $\begin{array}{l}\text { Chronic pain, } \\
\text { motion restriction }\end{array}$ & $\begin{array}{c}\text { Severe disc } \\
\text { displacement } \\
\text { without reduction, } \\
\text { severe disc } \\
\text { deformity, } \\
\text { degenerative hard } \\
\text { tissue changes }\end{array}$ \\
\hline V (late) & $\begin{array}{l}\text { Crepitus, variable } \\
\text { and episodic pain, } \\
\text { chronic motion } \\
\text { restriction }\end{array}$ & $\begin{array}{l}\text { Gross deformity } \\
\text { and or disc } \\
\text { perforation, } \\
\text { degenerative } \\
\text { arthritic. Changes } \\
\text { as osteophytes and } \\
\text { subcortical cysts. }\end{array}$ \\
\hline
\end{tabular}

Study design : Arthrocentesis was performed for all patients as follows: the surgical site was thoroughly disinfected. The auriculotemporal nerve was anaesthetized using Articaine $\mathrm{HCl} 4 \%$ with epinephrine 1:100,000 (Artpharmadent, Artpharma Co., Cairo, Egypt) and 27-gauge $35 \mathrm{~mm}$ dental needle (C-K Ject Premium, CK Dental Industry Co., Gyeonggi-DO, Korea). A line was then drawn from the center of the tragus to the outer canthus of the eye. Two points were marked to identify the articular fossa and the articular eminence. The first point (the posterior point) was $10 \mathrm{~mm}$ anterior to the tragus and $2 \mathrm{~mm}$ vertically below the line and the other (the anterior point) was $20 \mathrm{~mm}$ anterior to the tragus and $10 \mathrm{~mm}$ vertically below the line. One 26 -gauge needle was inserted at each point; however the posterior point was used to insert $500 \mathrm{~mL}$ of ringer's solution into the upper joint space, while the other was used for spontaneous solution outflow (Figure 1). 


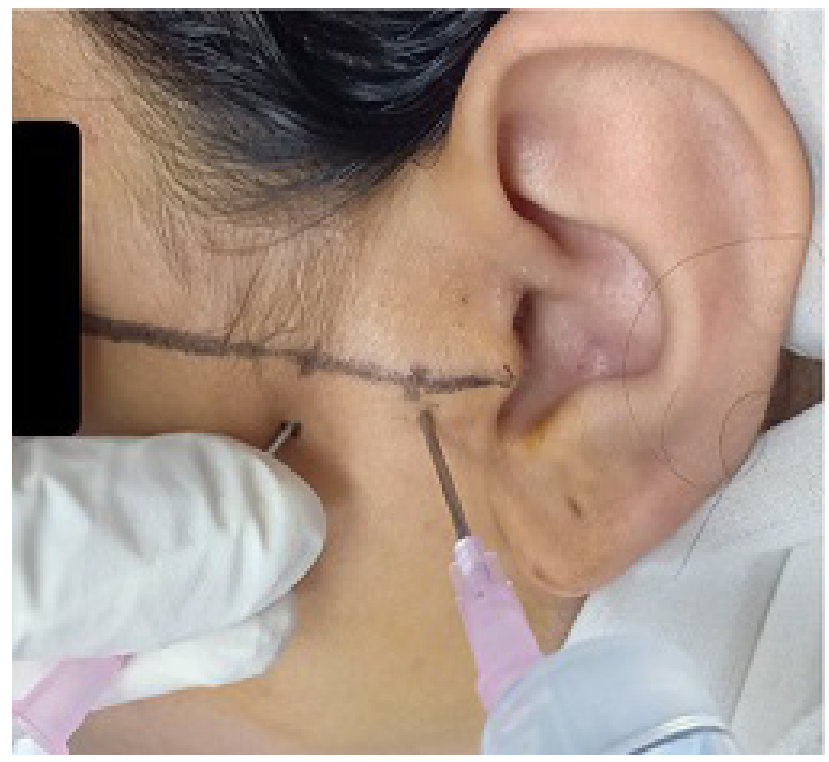

Fig 1: Arthrocentesis procedures

Then following arthrocentesis, for group I patients (the control group), intra-articular injection of $0.4 \mathrm{~mL}$ of $2 \%$ hyaluronic acid (Hyalgan, Fidiapharma, USA) was performed through the posterior point. However, after arthrocentesis for group II patients (the study group), $5 \mathrm{~mL}$ of the venous blood were withdrawn from the patient's antecubital vein into a sterile glass tube which was then immediately placed in the preprogrammed centrifuge device adjusted on $600 \mathrm{rpm}$ and 4 minutes centrifugation time. At the end of centrifugation process, the glass tube was collected. At the bottom of the glass tube, there was a blood clot and above it there was a liquid yellowish layer of i-PRF that remains in the liquid form for about 20 minutes (Figure 2). The upper-most liquid layer was collected with a syringe as shown in Figure 3 and then was injected into the joint as an intra-articular injectable i-PRF through the posterior point.

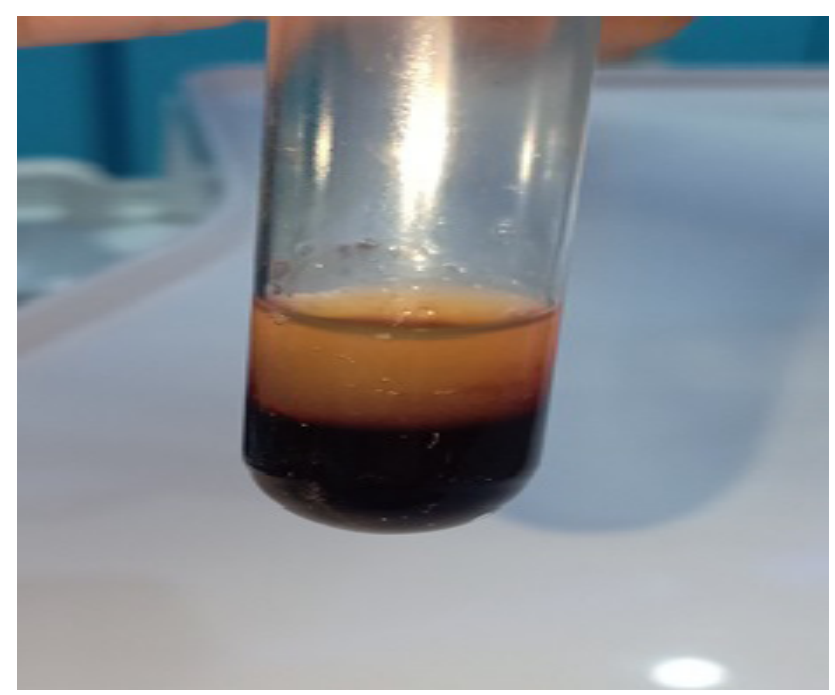

Fig. 2: The glass tube immediately after collection from the centrifuge device; above: is the i-PRF (the yellowish liquid), and below it is the blood clot

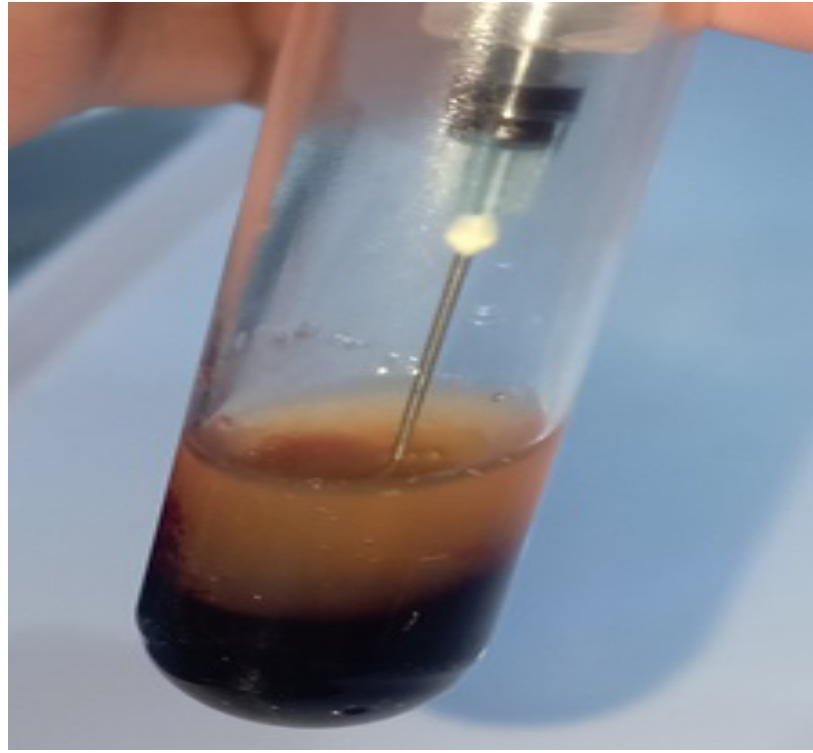

Fig. 3: Collecting the i-PRF with the use of a syringe

This study complied with the Declaration of Helsinki (revised in 1975), and with CONSORT (Consolidated Standards of Reporting Trials) principles and the regional ethical review board approved the study. All patients provided informed consent or assent as appropriate.

Investigated parameters : Clicking was investigated using a stethoscope to auscultate the join for presence of clicking. Pain intensity was recorded by asking the patient to make a mark that best described his pain level (if any) in the articular and or periarticular area (during rest or on function) on a visual analogue scale (VAS) form (a $10 \mathrm{~cm}$ line ranged from 0 to 10 , where 0 represented no pain and 10 represented the worst possible pain). The maximum mouth opening was recorded by measuring the maximum interincisal distance with a Vernier caliper. Presence of clicking, pain intensity, and MMO were recorded preoperatively and at one week, one month, and three months postoperatively.

Statistical analysis : Statistics were performed with SPSS software (version 19, IBM Co, USA).

\section{RESULTS}

The gender distribution between the members of population of the current study was insignificant (19 females and 11 males, $P=0.2004$; statistically insignificant difference). Table 2 depicts that both treatments resulted in clicking reduction, however, that was insignificant between both groups and intra-group at all postoperative investigation visits. Also, preoperative values had insignificant difference between both groups. While on comparing the preoperative value and the one-month-postoperative value for group I, the difference was statistically insignificant ( $\mathrm{X} 2=3.14, \mathrm{P}=0.77$ ), but was statistically significant for group II $(\mathrm{X} 2=4.8, P=0.029)$. The same applies if the comparison was with the three-monthspost-operative value; $(\mathrm{X} 2=3.14, \mathrm{P}=0.77)$ and $(\mathrm{X} 2=6.14$, $P=0.013)$, respectively. 
Table 2: Presence of clicking in both groups

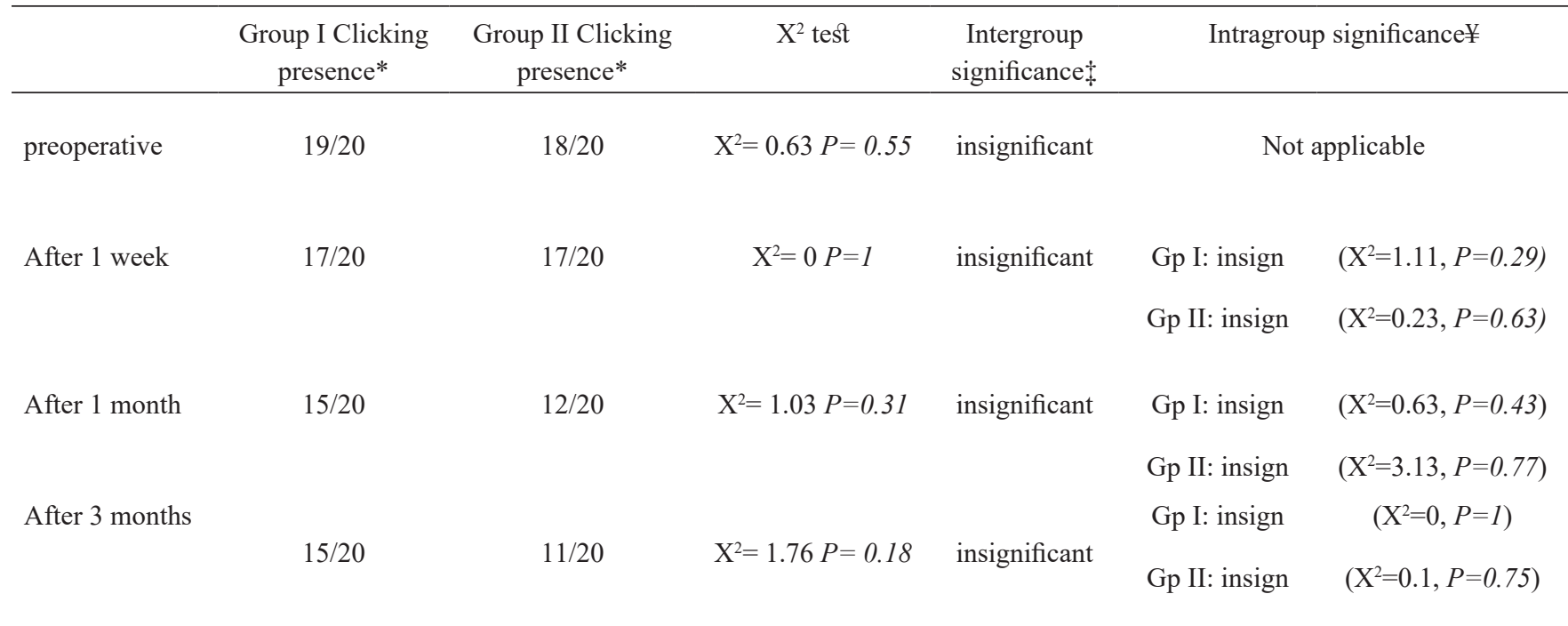

* the number of cases showing clicking in relation to the total number of the examined joints in the group; + the significance between the values of both groups at the same session at $\alpha=0.05$; $¥$ : the significance within each group tested to the values of the previous session at $\alpha=0.05$ (X2 test); Gp I: group I; Gp II: grop II; sign: significant; insign: insignificant

As table 3 depicts, pain level significantly decreased within both groups over time but after three months, it started to significantly increase once again. Pain level in group I was higher than that in group II at all postoperative visits. However, that was significant only at the first post-operative week. The preoperative difference was statistically insignificant.

Table 4 depicts that despite the preoperative difference was statistically insignificant, MMO has enhanced over time in both groups on successive visits, but not at three postoperative months. Moreover, in every visit, the enhancement in group II was better than that in group I.

These results were reflected in the improved disc position to gain more normal relation postoperatively after the anteriorly displaced position it showed preoperatively as shown in figures 4 and 5 .

Table 3: Pain score (using the numeric scale) for the both groups

\begin{tabular}{|c|c|c|c|c|c|c|}
\hline & $\begin{array}{c}\text { Group I } \\
\left(\text { mean } \pm \mathrm{SD}^{*}\right)\end{array}$ & $\begin{array}{c}\text { Group II } \\
\left(\operatorname{mean} \pm \mathrm{SD}^{*}\right)\end{array}$ & $\begin{array}{c}\text { Unpaired } \\
\text { student } t \text { test }\end{array}$ & $\begin{array}{c}\text { Intergroup } \\
\text { significance }\end{array}$ & \multicolumn{2}{|c|}{ Intragroup significance $¥$} \\
\hline preoperative & $5.9 \pm 0.5$ & $6.1 \pm 0.1$ & $\mathrm{t}=1.8 p=0.088$ & insignificant & \multicolumn{2}{|c|}{ Not applicable } \\
\hline After 1 week & $2.8 \pm 1.2$ & $1.8 \pm 0.7$ & $\mathrm{t}=3.2 P=0.0026$ & significant & $\begin{array}{l}\text { Gp I: sign } \\
\text { Gp II: sign }\end{array}$ & $\begin{array}{l}(\mathrm{t}=10.66, P<0.0001) \\
(\mathrm{t}=27.2, P<0.0001)\end{array}$ \\
\hline After 1 month & $0.2 \pm 0.1$ & $0.15 \pm 0.1$ & $\mathrm{t}=1.58 P=0.1221$ & insignificant & $\begin{array}{l}\text { Gp I: sign } \\
\text { Gp II: sign }\end{array}$ & $\begin{array}{l}(\mathrm{t}=9.66, P<0.0001) \\
(\mathrm{t}=10.44, P<0.0001)\end{array}$ \\
\hline After 3 months & $1 \pm 0.5$ & $0.8 \pm 0.3$ & $\mathrm{t}=1.534 p=0.1333$ & insignificant & $\begin{array}{l}\text { Gp I: sign } \\
\text { Gp II: sign }\end{array}$ & $\begin{array}{l}(\mathrm{t}=7.02, P<0.0001) \\
(\mathrm{t}=9.19, P<0.0001)\end{array}$ \\
\hline
\end{tabular}

* SD: Standard deviation; $¥$ : the significance between the values of both groups at the same session at $\alpha=0.05$; $¥$ : the significance within each group tested to the values of the previous session at $\alpha=0.05$ (paired t test); Gp I: group I; Gp II: grop II; sign: significant; insig: insignificant 
Table 4: The maximum mouth opening (in $\mathrm{mm}$ ) for the both groups

\begin{tabular}{|c|c|c|c|c|c|c|}
\hline & $\begin{array}{c}\text { Group I } \\
\left(\text { mean } \pm \mathrm{SD}^{*}\right)\end{array}$ & $\begin{array}{c}\text { Group II } \\
\left(\text { mean } \pm \mathrm{SD}^{*}\right)\end{array}$ & $\begin{array}{c}\text { Unpaired } \\
\text { student } t \text { test }\end{array}$ & $\begin{array}{l}\text { Intergroup } \\
\text { significance }\end{array}$ & \multicolumn{2}{|c|}{ Intragroup significance $¥$} \\
\hline preoperative & $27 \pm 1.5$ & $26 \pm 2.6$ & $t=1.49 p=0.145$ & insignificant & \multicolumn{2}{|c|}{ Not applicable } \\
\hline \multirow[t]{2}{*}{ After 1 week } & \multirow[t]{2}{*}{$35 \pm 1.1$} & \multirow[t]{2}{*}{$37 \pm 0.8$} & \multirow[t]{2}{*}{$t=6.85 P<0.0001$} & \multirow[t]{2}{*}{ significant } & Gp I: sign & $(\mathrm{t}=17.33, P<0.0001)$ \\
\hline & & & & & Gp II: sign & $(\mathrm{t}=18.35, P<0.0001)$ \\
\hline \multirow[t]{2}{*}{ After 1 month } & \multirow{2}{*}{$39 \pm 1.5$} & \multirow{2}{*}{$43.5 \pm 2.1$} & \multirow{2}{*}{$t=7.8 p<0.0001$} & \multirow{2}{*}{ significant } & Gp I: sign & $(\mathrm{t}=13.66, P<0.0001)$ \\
\hline & & & & & Gp II: sign & $(\mathrm{t}=12.1, P<0.0001)$ \\
\hline \multirow[t]{2}{*}{ After 3 months } & \multirow[b]{2}{*}{$39.2 \pm 1.4$} & \multirow[b]{2}{*}{$44 \pm 0.5$} & \multirow[b]{2}{*}{$t=14.44 p<0.0001$} & \multirow[b]{2}{*}{ significant } & Gp I: sign & $(\mathrm{t}=0.43, P=0.565)$ \\
\hline & & & & & Gp II: sign & $(\mathrm{t}=1.2, P=0.33)$ \\
\hline
\end{tabular}

* SD: Standard deviation; $¥$ : the significance between the values of both groups at the same session at $\alpha=0.05$; $¥$ : the significance within each group tested to the values of the previous session at $\alpha=0.05$ (paired t test); Gp I: group I; Gp II: grop II; sign: significant; insign: insignificant

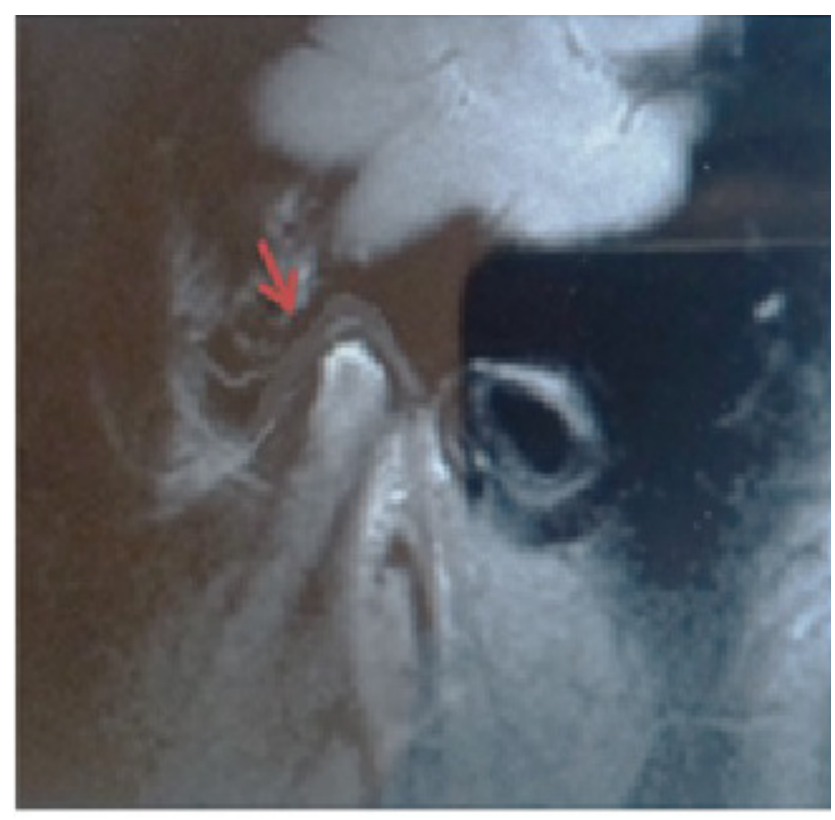

Fig. 4: MRI of a case preoperatively shows anterior disc displacement as the red arrow indicates

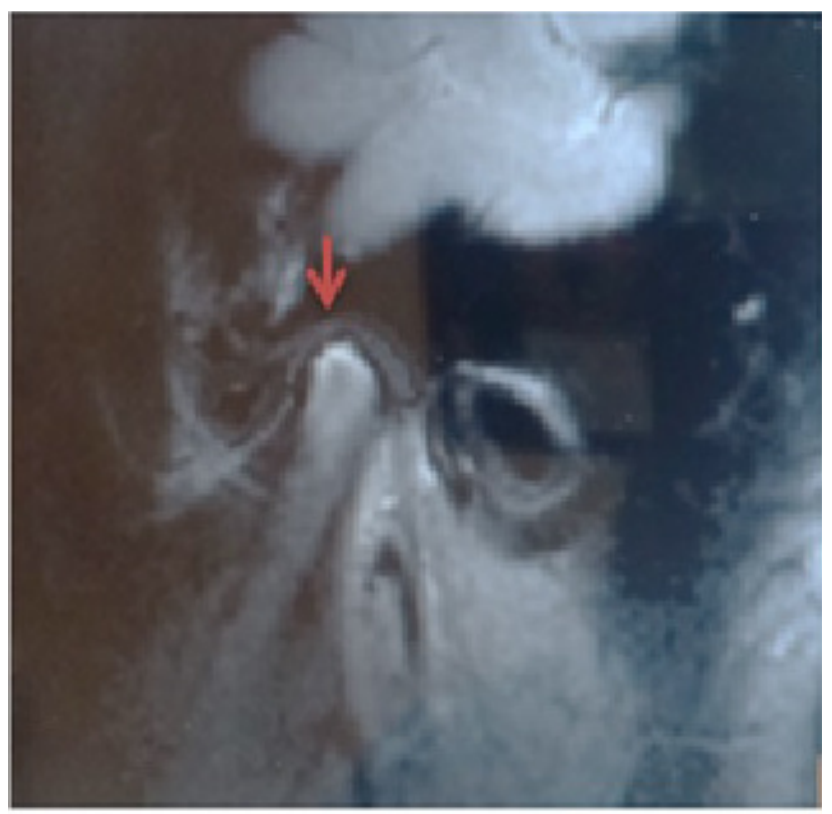

Fig. 5: MRI of a case postoperatively shows improvement of the disc position to gain a more normal relation as the red arrow indicates 


\section{DISCUSSION}

Internal derangement (ID) is the most common cause for temporomandibular joint disorder $(\mathrm{TMD})^{[1-3]}$. Arthrocentsis either followed with intraarticular injections or not was advocated as a minimally invasive therapy. Arthrocentesis leads to releasing the adhesions, alleviating intra-articular negative pressure, and washing out inflammatory mediators such as cytokines, and thereby it relieves pain and improves joint function ${ }^{[17-22]}$. Since Hyaluronic acid (HA) is the main constituent of the synovial fluid, it was widely utilized as an intra-articular injection therapy as a lubricant ${ }^{[21-24]}$. injectable PRF (i-PRF) is a very recently introduced regenerative material that contains higher concentrations of various growth factors and leukocytes rather than the ordinary PRF, and so it was introduced as a recent intra-articular injection material ${ }^{[25-29]}$. Therefore, the current study aimed at comparing the effect of the i-PRF with HA in cases of ID.

In the current study, clicking was reduced in both groups. These results are in agree with that of other studies ${ }^{[30,31]}$. With regards to pain, it was reduced in both groups. These results complies with various other reports ${ }^{[7,14,21,24-28]}$. At the third month, pain began to increase may be due to the need for treatment re-application. For MMO, i-PRF group recorded better results rather the HA group. Moreover, i-PRF achieved an improvement that was sustained all-over the follow up period. Pain reduction and better lubrication might allowed wider range of movement due to the enhanced mechanics and pain reduction which also might have decreased the incidence of trismus The better performance of i-PRF rather than HA go in agree with other studies ${ }^{[7,14,21,24-28]}$. That might be the result of its ability of i-PRF to release higher concentrations of multiple growth factors, to induce higher fibroblast migration, and to express PDGF, TGF- $\beta$, and collagen1 which all could collaborate to provide more enhanced environment for the regeneration and repair of the defects. Moreover, i-PRF had the ability to produce the HA itself through regenerating the synovial cells which secrete HA and in turn provide an endogenous and sustainable source of HA. HA had a lubricant action which allowed the disc to move more smoothly and with less friction in relation to the eminence especially after removing the adhesions, so that jerk disc movements were avoided and thus the clicking sound was reduced in addition to pain reducing effect. These effects synergized the effect of arthrocentesis which on its own had a pain reducing effect by washing out the inflammatory cytokines such as IL- $1 \beta$, TNF $\alpha$; and IL-6 and other noxious substances.

\section{CONCLUSION}

Internal derangement is the most common cause for TMDs. Arthrocentesis followed with various intra-articular medications have been attempted to treat ID. HA had a lubricant effect that improves joint movement and reduced friction pain. However, i-PRF had both anti-inflammatory actions to reduce the level of the cytokines; aided by the regenerative capacity to the torn and degenerated tissues of the joint including the synovial tissue. Regeneration improves the joint function, allows smoother movement and reduces pain, and provides endogenous sustained source of HA. That could attribute for the better results achieved by i-PRF than HA in the scope of the current study. Although both modalities are accepted, i-PRF is more recommended.

\section{CONFLICT OF INTEREST}

There are no conflicts of interests.

\section{REFERENCES}

1. H. A. Israel, "Internal Derangement of the Temporomandibular Joint: New Perspectives on an Old Problem," Oral and Maxillofacial Surgery Clinics of North America, vol. 28, no. 3. W.B. Saunders, pp. 313-333, Aug. 01, 2016, doi: 10.1016/j.coms.2016.03.009.

2. C. H. Wilkes, "Internal Derangements of the Temporomandibular Joint: Pathological Variations," Arch. Otolaryngol. Neck Surg., vol. 115, no. 4, pp. 469-477, 1989, doi: 10.1001/ archotol.1989.01860280067019.

3. G. Dimitroulis, "Management of temporomandibular joint disorders: A surgeon's perspective," Aust. Dent. J., vol. 63, pp. S79-S90, Mar. 2018, doi: 10.1111/adj.12593.

4. E. Machado, P. Machado, and P. A. Cunali, "Use of chondroitin sulphate and glucosamine sulphate in degenerative changes in TMJ: A systematic review," Dental Press J. Orthod., vol. 17, no. 4, pp. 19-20, 2012, doi: 10.1590/s217694512012000400006 .

5. I. Damlar, E. Esen, and U. Tatli, "Effects of glucosamine-chondroitin combination on synovial fluid IL-1 $\beta$, IL-6, TNF- $\alpha$ and PGE2 levels in internal derangements of temporomandibular joint," Med. Oral Patol. Oral Cir. Bucal, vol. 20, no. 3, pp. e278-e283, May 2015, doi: 10.4317/ medoral.20242.

6. S. Mummolo et al., "Ultra-low-frequency transcutaneous electric nerve stimulation (ULF-TENS) in subjects with craniofacial pain: A retrospective study," CRANIO ${ }^{\circledR}$, vol. 38 , no. 6 , pp. 396-401, Nov. 2020, doi: 10.1080/08869634.2018.1526849. 
7. C. Efeoglu, A. S. Calis, H. Koca, and E. Yuksel, "A stepped approach for the management of symptomatic internal derangement of the temporomandibular joint," J. Otolaryngol. - Head Neck Surg., vol. 47, no. 1, p. 33, May 2018, doi: 10.1186/s40463-018-0282-y.

8. G. Bouloux, M. G. Koslin, G. Ness, and D. Shafer, "Temporomandibular Joint Surgery," J. Oral Maxillofac. Surg., vol. 75, no. 8, pp. e195-e223, Aug. 2017, doi: 10.1016/j.joms.2017.04.027.

9. A.Zwiri et al., "Biomarkers fortemporomandibular disorders: Current status and future directions," Diagnostics, vol. 10, no. 5. MDPI AG, May 01, 2020, doi: 10.3390/diagnostics 10050303 .

10. N. J. AbdulRazzak, J. A. Sadiq, and A. T. Jiboon, "Arthrocentesis versus glucocorticosteroid injection for internal derangement of temporomandibular joint," Oral Maxillofac. Surg., 2020, doi: 10.1007/s10006-020-00901-3.

11. C. Di Paolo, G. Falisi, F. Panti, P. Di Giacomo, and A. Rampello, "RA.DI.CA.' splint for the management of the mandibular functional limitation: A retrospective study on patients with anterior disc displacement without reduction," Int. J. Environ. Res. Public Health, vol. 17, no. 23, pp. 1-12, Dec. 2020, doi: 10.3390/ijerph17239057.

12. A. A. Ilyin, T. A. Fazylova, E. A. Demchinsky, V. N. Olesova, and E. E. Olesov, "A complex treatment of irreducible displacement of the temporomandibular joint disc and myofascial pain disorders with the use of botulinum toxin," J. Clin. Pract., vol. 10, no. 2, pp. 14-20, Aug. 2019, doi: 10.17816/clinpract10214-20.

13. L. B. Calixtre, R. F. C. Moreira, G. H. Franchini, F. Alburquerque-Sendín, and A. B. Oliveira, "Manual therapy for the management of pain and limited range of motion in subjects with signs and symptoms of temporomandibular disorder: A systematic review of randomised controlled trials," Journal of Oral Rehabilitation, vol. 42, no. 11. Blackwell Publishing Ltd, pp. 847-861, Nov. 01, 2015, doi: 10.1111/joor.12321.

14. J. B. Albilia, C. H. Vizcaíno, H. Weisleder, J.
Choukroun, and S. Ghanaati, "Liquid platelet-rich fibrin injections as a treatment adjunct for painful temporomandibular joints: preliminary results," Cranio - J. Craniomandib. Pract., vol. 38, no. 5, 2018, doi: 10.1080/08869634.2018.1516183.

15. A. Malik, "Internal derangement of temporomandibular joint: role of arthocentesis with steriod," Plast. Aesthetic Res., vol. 1, no. 1, p. 29, Jun. 2014, doi: 10.4103/2347-9264.135547.

16. K. Briggs, O. Breik, K. Ito, and A. Goss, "Arthrocentesis in the management of internal derangement of the temporomandibular joint," Aust. Dent. J., vol. 64, no. 1, pp. 90-95, Mar. 2019, doi: 10.1111/adj.12665.

17. M. Nishimura, N. Segami, K. Kaneyama, J. Sato, and K. Fujimura, "Comparison of Cytokine Level in Synovial Fluid between Successful and Unsuccessful Cases in Arthrocentesis of the Temporomandibular Joint," J. Oral Maxillofac. Surg., vol. 62, no. 3, pp. 284-287, 2004, doi: 10.1016/j.joms.2003.08.012.

18. E. Grossmann, R. L. Poluha, L. C. V. Iwaki, R. G. Santana, and L. I. Filho, "The use of arthrocentesis in patients with temporomandibular joint disc displacement without reduction," PLoS One, vol. 14, no. 2, Feb. 2019, doi: 10.1371/journal. pone.0212307.

19. A. Soni, "Arthrocentesis of temporomandibular joint-Bridging the gap between non-surgical and surgical treatment," Annals of Maxillofacial Surgery, vol. 9, no. 1. Wolters Kluwer Medknow Publications, pp. 158-167, Jan. 01, 2019, doi: 10.4103/ams.ams_160_17.

20. C.-W. Kim et al., "Effect of arthrocentesis on the clinical outcome of various treatment methods for temporomandibular joint disorders," Maxillofac. Plast. Reconstr. Surg., vol. 41, no. 1, Dec. 2019, doi: 10.1186/s40902-019-0227-z.

21. M. Sikora, B. Czerwińska-Niezabitowska, M. A. Chęciński, M. Sielski, and D. Chlubek, "Short-Term Effects of Intra-Articular Hyaluronic Acid Administration in Patients with Temporomandibular Joint Disorders," J. Clin. 
Med., vol. 9, no. 6, p. 1749, Jun. 2020, doi: $10.3390 / \mathrm{jcm} 9061749$.

22. G. De Riu et al., "Arthrocentesis and temporomandibular joint disorders: Clinical and radiological results of a prospective study," Int. J. Dent., vol. 2013, 2013, doi: 10.1155/2013/790648.

23. W. Yang, W. Liu, C. Miao, H. Sun, L. Li, and C. Li, "Oral Glucosamine Hydrochloride Combined With Hyaluronate Sodium Intra-Articular Injection for Temporomandibular Joint Osteoarthritis: A Double-Blind Randomized Controlled Trial," J. Oral Maxillofac. Surg., vol. 76, no. 10, pp. 2066 2073, Oct. 2018, doi: 10.1016/j.joms.2018.04.031.

24. Y. Liu, J. shun Wu, Y. ling Tang, Y. jie Tang, W. Fei, and X. hua Liang, "Multiple Treatment Meta-Analysis of Intra-Articular Injection for Temporomandibular Osteoarthritis," Journal of Oral and Maxillofacial Surgery, vol. 78, no. 3. W.B. Saunders, pp. 373.e1-373.e18, Mar. 01, 2020, doi: 10.1016/j.joms.2019.10.016.

25. J. Choukroun and S. Ghanaati, "Reduction of relative centrifugation force within injectable platelet-rich-fibrin (PRF) concentrates advances patients' own inflammatory cells, platelets and growth factors: the first introduction to the low speed centrifugation concept," Eur. J. Trauma Emerg. Surg., vol. 44, no. 1, pp. 87-95, Feb. 2018, doi: $10.1007 / \mathrm{s} 00068-017-0767-9$.

26. Z. Kargarpour, J. Nasirzade, L. Panahipour, R. J. Miron, and R. Gruber, "Relative centrifugal force (Rcf; g-force) affects the distribution of $\operatorname{tgf}-\beta$ in prf membranes produced using horizontal centrifugation," Int. J. Mol. Sci., vol. 21, no. 20, pp. 1-12, Oct. 2020, doi: 10.3390/ijms21207629.
27. S.-L. Lin, C.-C. Tsai, S.-L. Wu, S.-Y. Ko, W.-F. Chiang, and J. W. Yang, "Effect of arthrocentesis plus platelet-rich plasma and platelet-rich plasma alone in the treatment of temporomandibular joint osteoarthritis," Medicine (Baltimore),, vol. 97, no. 16, p. e0477, Apr. 2018, doi: 10.1097/ MD.0000000000010477.

28. Z. Chen, C. Wang, D. You, S. Zhao, Z. Zhu, and M. Xu, "Platelet-rich plasma versus hyaluronic acid in the treatment of knee osteoarthritis: A meta-analysis," Medicine (Baltimore), vol. 99, no. 11, p. e19388, Mar. 2020, doi: 10.1097/ MD.0000000000019388.

29. S. G. Kutuk, G. Gökçe, M. Arslan, Y. Özkan, K. Mustafa, and O. K. Arikan, "Clinical and radiological comparison of effects of platelet-rich plasma, hyaluronic acid, and corticosteroid injections on temporomandibular joint osteoarthritis," J. Craniofac. Surg., vol. 30, no. 4, pp. 1144-1148, 2019, doi: 10.1097/ SCS.0000000000005211.

30. S. E. Widmalm, Y. Dong, B. X. Li, M. Lin, L. J. Fan, and S. M. Deng, "Unbalanced lateral mandibular deviation associated with TMJ sound as a sign in TMJ disc dysfunction diagnosis," J. Oral Rehabil., vol. 43, no. 12, pp. 911-920, Dec. 2016, doi: 10.1111/joor.12446.

31. S.-Y. Moon, S.-T. Lee, and J.-W. Ryu, "Ultrasoundguided Platelet-rich Plasma Prolotherapy for Temporomandibular Disorders," J. Oral Med. Pain, vol. 39, no. 4, pp. 140-145, Dec. 2014, doi: 10.14476/jomp.2014.39.4.140 